\title{
IDŐJÁRÁS
}

Quarterly Journal of the Hungarian Meteorological Service

Vol. 123, No. 1, January-March, 2019, pp. 73-87

\section{Investigation of soybean leaf area influenced by water supply}

\author{
Angela Anda*, Brigitta Simon, Gábor Soós, László Menyhárt, \\ and Tamás Kucserka \\ Department of Meteorology and Water Management, \\ University of Pannonia, Georgikon Faculty, \\ Deák Ferenc u. 16, H-8360 Keszthely, Hungary
}

*Corresponding authorE-mail: anda-a@georgikon.hu; anda@keszthelynet.hu

(Manuscript received in final form April 25, 2018)

\begin{abstract}
Soybean leaf area observations were carried out in two levels of water supply using two different varieties (Sinara and Sigalia) in Hungary. Half of the crops was grown using unlimited watering in evapotranspirometers, while the others received only $50 \%$ of their water requirements from the R1 (beginning bloom) stage (stressed crops). Out of four meteorological variables, the air temperature, the most easily accessible meteorological variable impacted the $L A I$ (leaf area index) the most, irrespective of water supply. To obtain the variation in the vertical leaf area distribution, the $L A I_{\max }$ was selected and analyzed, when leaf area remained relatively invariable. Water deprivation in the reproductive phase significantly reduced the $L A I$, irrespective of the studied variety. The water stress condition significantly lowered the level-wise trifoliate area of Sigalia above the sixth leaf level but did not lower it in the case of Sinara. Increase of 1.5 in the number of leaf levels could be contributed to the higher $L A I$ of crops with unlimited watering in comparison to water stressed ones. The area of the middle leaflet was significantly higher compared to the outer ones at the bottom and the top of the plant, but they were of about the equal size around the center of the plant height irrespective of the variety. According to our best knowledge, this morphological phenomenon has not been described yet.
\end{abstract}

Key-words: distribution of leaf area, soybean (Glycine max L.), evapotranspiration, water stress

\section{Introduction}

Leaf assimilatory surface size, photosynthesis, and crop biomass are the main crop indicators of final yield (Kross et al. 2015) including soybean. Most commonly, the ratio of the green leaf area in $\mathrm{m}^{2}$ to the ground surface area (in $\mathrm{m}^{2}$ ) 
is expressed as leaf area index, LAI. Green leaf area is available for gas exchange processes (mainly $\mathrm{CO}_{2}$ and water vapor) between the canopy and the atmosphere. Vina et al. (2011) specified these vegetation processes, including light and water interception (rainfall and fog), light attenuation through the crop stand, transpiration, photosynthesis, autotrophic respiration, and carbon and different nutrients' cycles. Yang et al. (2009) identified that the size of maximum LAI reflected the impacts of environmental conditions the most. Malone et al. (2002) concluded the soybean $L A I$ reaches 3.5-4.0 in the growth stages from R2 (full bloom) to R5 (beginning seed) producing high seed yield. Similar values were also published by Board et al. (1997). In soybean evapotranspiration (EVTR), "threshold" LAI of 3.7 was communicated by Campos et al. (2017) at the University of Nebraska-Lincoln Research Centre, USA after which further growth in $L A I$ does not increase canopy's evapotranspiration. This peak $L A I$ was called as "saturation $L A I$ " after Bausch (1993). In this study, the peak $L A I$ was selected and analyzed from the growing period of soybean, where $L A I$ remained relatively invariable (August). Selected time periods were also suitable for comparative water withdrawal investigations as growth stages between R4 (full pod) and R6 (full seed) are vulnerable to water deficiencies producing in significant yield loss (Bagg et al. 2009). Hsiao (1990) also highlighted LAI as affected by water stress as an important indicator of crop growth and final yield.

The green colored part of crop leaves is the photosynthetically active component which must be separated from the dried leaves.

Two main types of approaches were developed in the LAI estimation; direct (based on leaf collection) and indirect methods. In this second group, LAI is derived from one or more easily measurable leaf characteristics (Jonckheere et al. 2004). Indirect non-contact measurements are considered to be the most up-todate, and non-destructive $L A I$ observation group using remotely sensed canopy reflectance data that has been reviewed partially by Verrelst et al. (2015). Although it does not mean that other $L A I$ estimation methods can not be of great significance under special circumstances.

The aim of this investigation was to find a simplified approach in soybean's leaf area estimation that allows easy experimental evaluation of the assimilatory (transpiration) surface size. Leaf area estimation (in the absence of planimeter) using empirical functions based on meteorological variables was also a vital part of the study target. The variation in the vertical distribution of the leaf area across two soybean varieties of three different water supply levels was also documented. To date, there are only limited number of studies that have attempted to take soybean leaflet area into account. Leaf area parameters are basic inputs for most of the crop models. 


\section{Materials and methods}

Soybean (Glycine max L.) and meteorological observations were carried out at the Keszthely Agrometeorological Research Station (ARS) (latitude: 46 $44^{\prime} \mathrm{N}$, longitude: $17^{\circ} 14^{\prime} \mathrm{E}$, elevation: $124 \mathrm{~m}$ above sea level), over the vegetation period of 2017. A QLC-50 climate station fitted with a CM-3 pyranometer was operated at ARS. This standard station belongs to the Hungarian National Meteorological Network operated by the Hungarian Meteorological Service (OMSZ). On the recommendation of the seed supplier company of Karintia (2017), indeterminate Sinara (Sin), a water stress tolerant, and Sigalia (Sig), a variety bred for average weather conditions were included in the study. The length of the studied soybean's growing season ranged between 116 and 120 days. Soybean hand sowing occurred on May 9, 2017, and crops successfully emerged on May17, 2017. The planting distance between the crop rows was $0.24 \mathrm{~m}$ (planting population: 600,000 seed ha $^{-1}$ ). Before planting, $300 \mathrm{~kg} \mathrm{ha}^{-1}$ nitrogen-phosphorus-potassium (NPK) fertilizer was applied at the time of sowing (N:P:K=1:1:1).

The phenological phases of soybean were used after Fehr and Caviness (1977).

Some of the treatments were grown in the growing pots of Thornthwaitetype compensation evapotranspirometers. Half of them got unlimited water supply in line with the nature of the equipment (ET). Stressed soybean canopies received only $50 \%$ of their water requirement from the reproductive phase (R1), producing detectable water stress conditions $(R O)$. The stressed vessels' control system (magnetic swimmer and Reed-switch) were disconnected and its water supplier switch was connected to the non-stressed vessel's reed switch, so the stressed vessel's water supply was regulated by the non-stressed water compensation unit. Water deprivation of stressed crops was ensured by closing the water supplier tap every second day. This setup allowed to reduce water supply in about half of the reproductive stage. A data logger of HYGACQ V1.3 type was connected to $\log$ the amount of water use. The calculated hourly sums were memorized. The collected hourly data were downloaded to a computer, using the WHYGACQ program (Anda and Soós, 2014). As stressed crop's tap was closed every second day, pentad sums and evapotranspiration totals were calculated (water balance) and presented in the study.

Altogether, two water treatments and two varieties were included in the study with the following experimental design:

- Sin ET (water stress tolerant variety, unlimited water supply);

- Sig ET (variety of average weather conditions, unlimited water supply);

- $\operatorname{Sin} R O$ (water stress tolerant variety, crops exposed to moisture stress from generative phase, R1);

- Sig RO (variety of average weather conditions, crops exposed to moisture stress from generative phase, R1). 
The leaflet area, $L$ was determined as follows. Given the oval shape of the leaflets, the area was expected to be directionally proportional to the product of the length $(a)$ and width $(b)$. The parameter $(a)$ was measured from the base of the leaf to the terminal part of the leaf blade. The maximum width of the leaflet (b) was taken at the widest lobes of the lamina perpendicular to the lamina midrib:

$$
L=x \cdot a b .
$$

In addition, destructive $L$ measurement using segmentation was carried out from separate growing pots excluded from the water supply study. Each leaflet was placed on a flat surface of an evenly colored red cardboard with a scale at the side, directly under a vertically mounted camera (Canon EOS 7D digital camera with 17.9 megapixels. Histogram based threshold segmentation was applied in the image processing program (SGDIP 0.1; of our own) to count the area of the region of interest.

The $x$ multiplier in Eq. (1) was determined with linear regression without intercept based on about 350 trifoliates.

Plant height of the crops was also registered for the same crops where $L$ measurements were carried out.

The effect of the water supply on the trifoliate level was analyzed with a 3-way ANOVA method. The area of the trifoliate was the response variable, the water supply, the variety of the plants, and the trifoliate level were considered as exploratory variables. In the first step, all 2-way and 3-way interactions were included in the model. Iteratively, the non-significant interaction and main effect with the highest $p$-value was removed from the model. Tukey HSD posthoc test was used, if it is necessary.

The area of the middle leaflet compared to the outer ones within a trifoliate was examined. The proportion of the middle leaflet within the whole trifoliate was calculated for each trifoliate level of each plant. Given the two outer leaflet are of about equal size, the proportion being greater than $1 / 3$ implies that the middle leaflet is larger than the outer ones. This proportion was analyzed with a 3-way ANOVA method on the same way as described at the analysis of the area of the trifoliate level.

Two-tailed one-sample $t$-test was applied to compare the proportion of the middle leaflet assumed to be $1 / 3$ of trifoliate area, on each trifoliate level, separately. Pooled standard deviation was used in the $t$-test. To facilitate the presentation of the results, $95 \%$ confidence interval was calculated for each trifoliate level. All plants were considered as a single sample.

To illustrate the impact of meteorological elements (air temperature, $T_{a}$; water vapor pressure, $e_{a}$; wind speed, $u$; precipitation, $P$ ) on $L A I$, the Pearson's correlation analysis was applied. Multiple stepwise regression analysis was carried out to get the combined effect of different meteorological variables on 
$L A I$. The Akaike information criterion $(A I C)$ was applied to estimate different $L A I$ projections (Motulsky and Christopoulos, 2004):

$$
A I C=N \times \ln \left(\frac{S S}{N}\right)+2 K
$$

where $N$ is the number of data points, $K$ is the number of parameters fit by the regression plus one, $S S$ is the residual sum of squares value taken from the ANOVA-table of the regression analysis. The model with the smallest $A I C$ value is most likely to be correct.

The tests were carried out with the SPSS Statistics software (IBM Corp., New York, USA) and R statistical software (R, 2017).

\section{Results and discussion}

\subsection{Weather, crop development, and evapotranspiration (EVTR)}

On a soybean seasonal average basis, the vegetation period in 2017 was $1.3^{\circ} \mathrm{C}$ warmer $(p<0.622)$ than that of the long-term mean at Keszthely (1971-2000). Warmer months were particularly noticeable in summer (June-August), when the difference from the climate norms was $1.8-2.7^{\circ} \mathrm{C}$. The growing season's precipitation sum $P$ was $37.0 \mathrm{~mm}$ lower $(p<0.738)$ than that of the long-term $P$ total $(384.4 \mathrm{~mm})$. Monthly $P$ sums in the growing season reduced with $17.4-37.4 \mathrm{~mm}$ in comparison to their climate norms (1971-2000). Although the distribution of monthly $P$ sum was quite even during the soybean growing season in 2017 . The only increased $P$ in September was out of the soybean's vegetation period.

Durations of the soybean phenological stages were similar across all treatments (data not shown). The maximum difference in the length of the vegetation periods was only restricted to a few days ( $1-2$ days).

Barely different seasonal daily mean EVTR rates of 5.88 and $5.63 \mathrm{~mm}^{\text {day }}{ }^{-1}$ was measured in Sin ET and Sig ET, respectively. Using unlimited watering, increase of $4.51 \%$ in daily average EVTR rate of $\operatorname{Sin} E T$ was not significant ( $p<0.224)$, indicating no variation in EVTR rates between the two varieties with different water requirements. Irrespective of variety, $50 \%$ water withdrawal of the crop water requirement declined the seasonal daily mean EVTR rate by more than half (Sin: $74.68 \%, p<0.001 ;$ Sig: 75.51\%, $p<0.001$ ). Surprisingly, there was no significant impact of variety on daily mean $E V T R$ rates at both water supply levels (ET: $4.51 \%, p<0.224 ; R O: 5.48 \%, p<0.165$ ). Even over water deprivation, the variety $\operatorname{Sin}$ bred for water shortage conditions statistically used the same amount of water as Sig.

Distribution in evapotranspiration pentad sums followed the usual pattern (Fig. 1); the peak 5-day evapotranspiration sums in the middle of the growing 
season were $51.6(\mathrm{Sin})$ and $57.4 \mathrm{~mm} \mathrm{pentad}^{-1}(\mathrm{Sig})$ for the $E T$ in the middle of July, and 23.0 (Sin) and $24.7 \mathrm{~mm} \mathrm{pentad}^{-1}(\mathrm{Sig})$ for the $R O$ treatments, respectively, in the middle of August. Top water losses of water deprived treatments were late about one month in comparison to unlimited the water supply treatment. From the beginning of August, variety Sin generally had higher peak 5-day EVTR sums than the variety Sig in both water supplies. In August, the stressed soybean probably "addicted" to water shortage, and the evapotranspiration curves of $R O$ got closer to the evapotranspiration curves of $E T$.

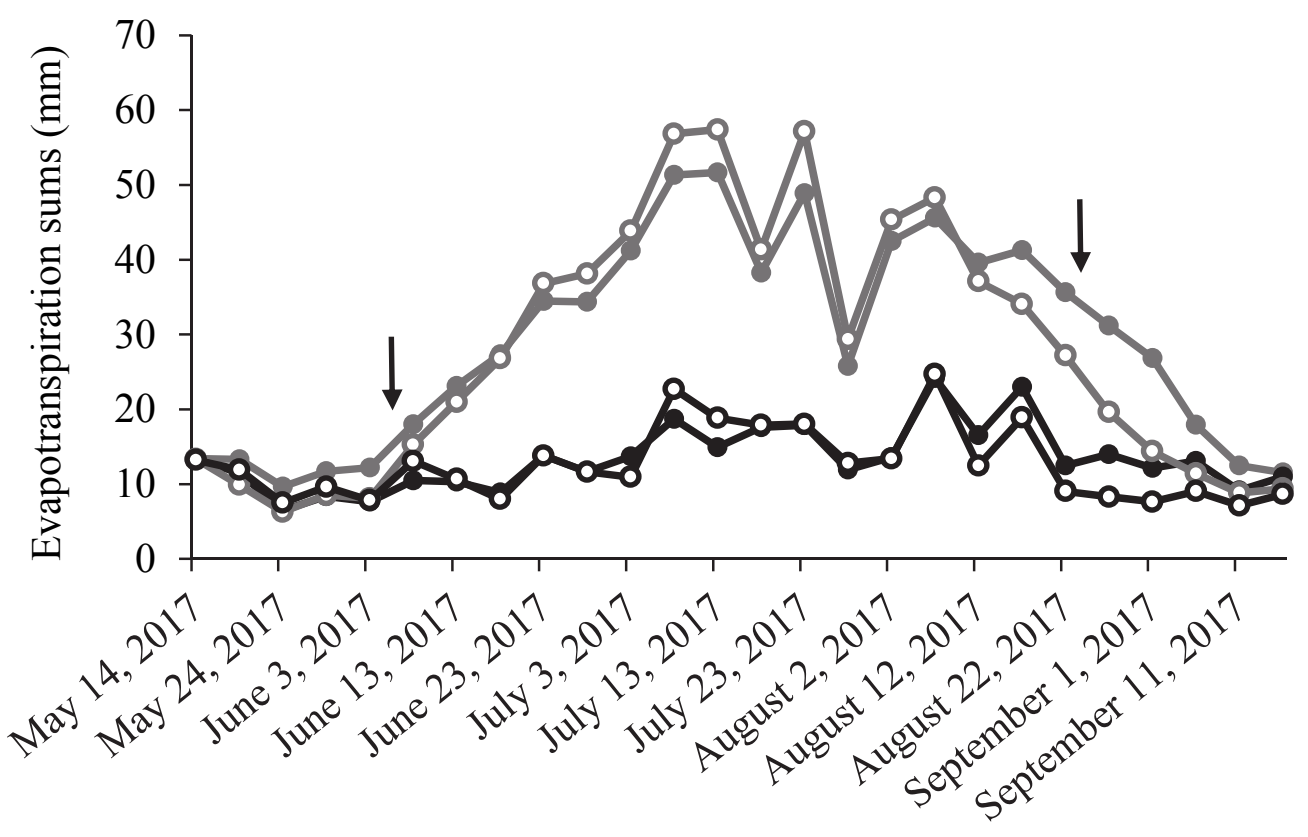

Pentads

$\rightarrow$ Sin ET $\rightarrow$ Sin $R O \quad \longrightarrow$ Sig ET $\rightarrow$ Sig RO

Fig. 1. Pentad sums of evapotranspiration in two soybean varieties (Sinara (Sin) and Sigalia (Sig)), using unlimited (ET) and water stressed (RO) canopies at Keszthely, during 2017. The arrows show the beginning and end of water deprivation.

The cumulative EVTR of 346.4 and $327.9 \mathrm{~mm}$ in Sin RO and Sig RO, respectively, stayed near the cumulative $P$ of the growing period (2017: 347.4 mm) (Fig. 2). EVTR totals of both ET treatments (Sin: $759.3 \mathrm{~mm}$; Sig: $725.8 \mathrm{~mm}$ ) were about twice as high as the cumulative seasonal $P$ at Keszthely, indicating that soil water coming from $P$ probably would not be enough to satisfy soybean water needs. Montoya et al. (2017) reported similar EVTR totals ranging from about 400 to $800 \mathrm{~mm}$ for rainfed and 50-75\% deficit irrigated soybeans (cultivar Don Mario) in Uruguay $\left(31^{\circ} 22^{\prime} \mathrm{S}\right)$. 


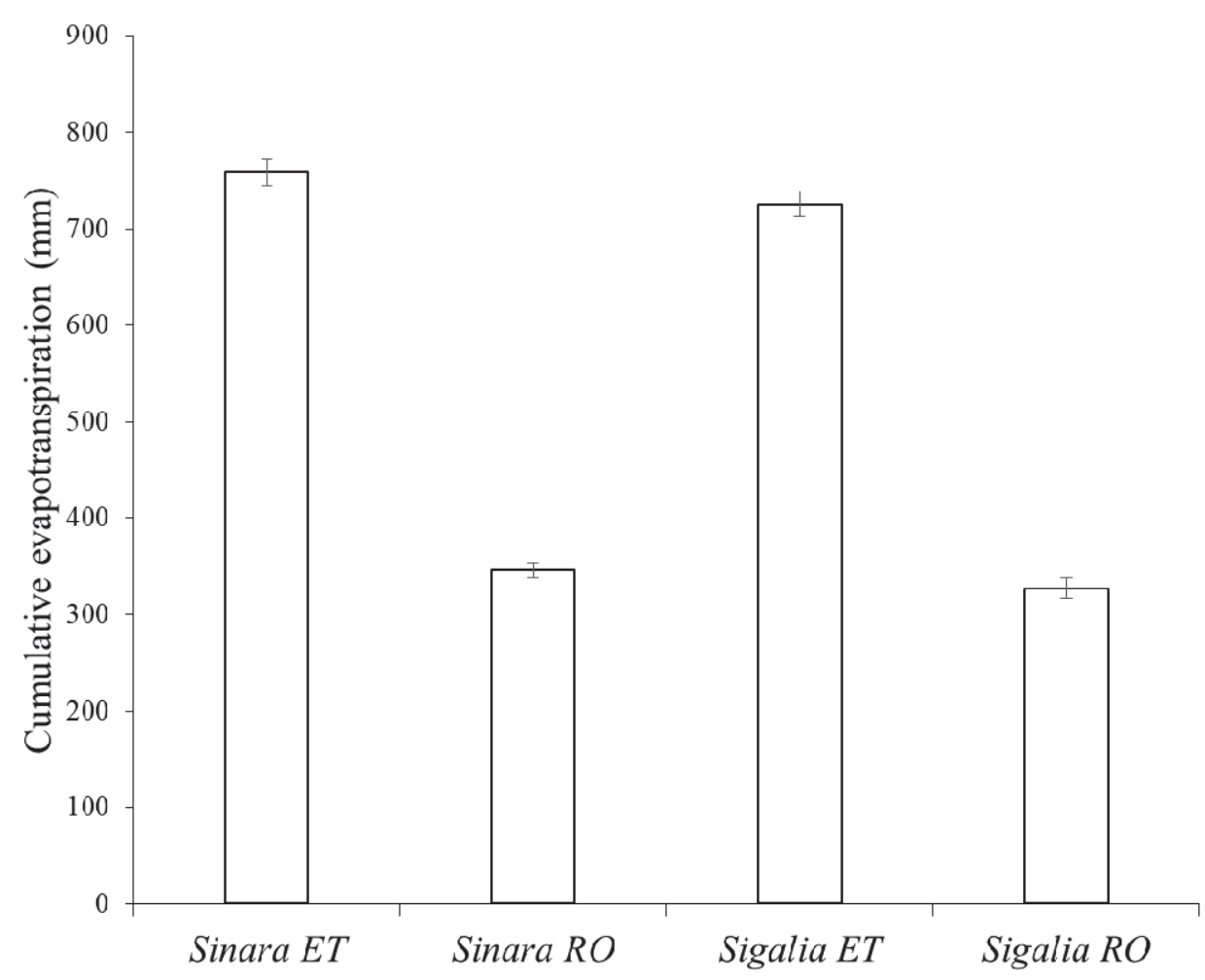

Fig. 2. Cumulative evapotranspiration of the two varieties Sinara (Sin) and Sigalia (Sig) using two levels of water supply; unlimited $(E T)$ and water stressed $(R O)$ canopies at Keszthely, during 2017.

\subsection{Seasonal variation in $L A I$}

Until photosynthesis shows an immediate response to environmental conditions, crop growth is the end result of photosynthesis, responds more slowly to environmental variation (Lessmann et al. 2001). This is why consecutive tracking of $L A I$ is appropriate in crop growth monitoring.

$L A I$ of soybean showed a period of increase that followed by a maximum value maintained for a shorter time period before decreasing. Weekly mean $L A I$ increased from a minimum of 0.3 on June 6 to a maximum of 9.6 (both $E T$ ) on August 2 (Fig. 3). $L A I_{\max }$ of 6.5 in $\operatorname{Sin} R O$ was only slightly lower than that of $L A I_{\max }=7.0$ measured by Montoya et al. (2017) in soybean (cultivar: Don Mario) at Salto, Uruguay ( $31^{\circ} 22^{\prime}$ S). Setiyono et al. (2008) also detected somewhat lower $L A I_{\max }$ of 7.8 in irrigated soybean (variety P93M11) at Lincoln, NE $\left(40^{\circ} 49^{\prime} \mathrm{N}\right)$. Natural senescence slightly declined the $L A I$ to a value of $0.1(R O)$. Seasonal mean $L A I$ ranged from 5.3 ( $\mathrm{Sin} E T)$ to $3.0(\mathrm{Sig} R O)$ over the growing season of 2017. Only, like a tendency, the seasonal mean LAI in Sin tended to be 1.9 (ET; $p<0.349)$ and $12.4 \%(R O ; p<0.154)$ higher than that of the average LAI of Sig. In turn, the seasonal mean $L A I$ of both varieties were strongly impacted by water deprivation. Declines of $39.4(p<0.001)$ and $49.3 \%(p<0.001)$ in water stressed $\mathrm{Sin}$ and Sig were observed, respectively, in comparison to LAI of crops with 
unlimited watering. Kross et al. (2015) explained lower soybean LAI under dryer conditions to have resulted from a greater investment in the root structure. Descending branch of weekly $L A I$ curve was slightly steeper in the water stressed pots than that of in the $E T$ treatments.

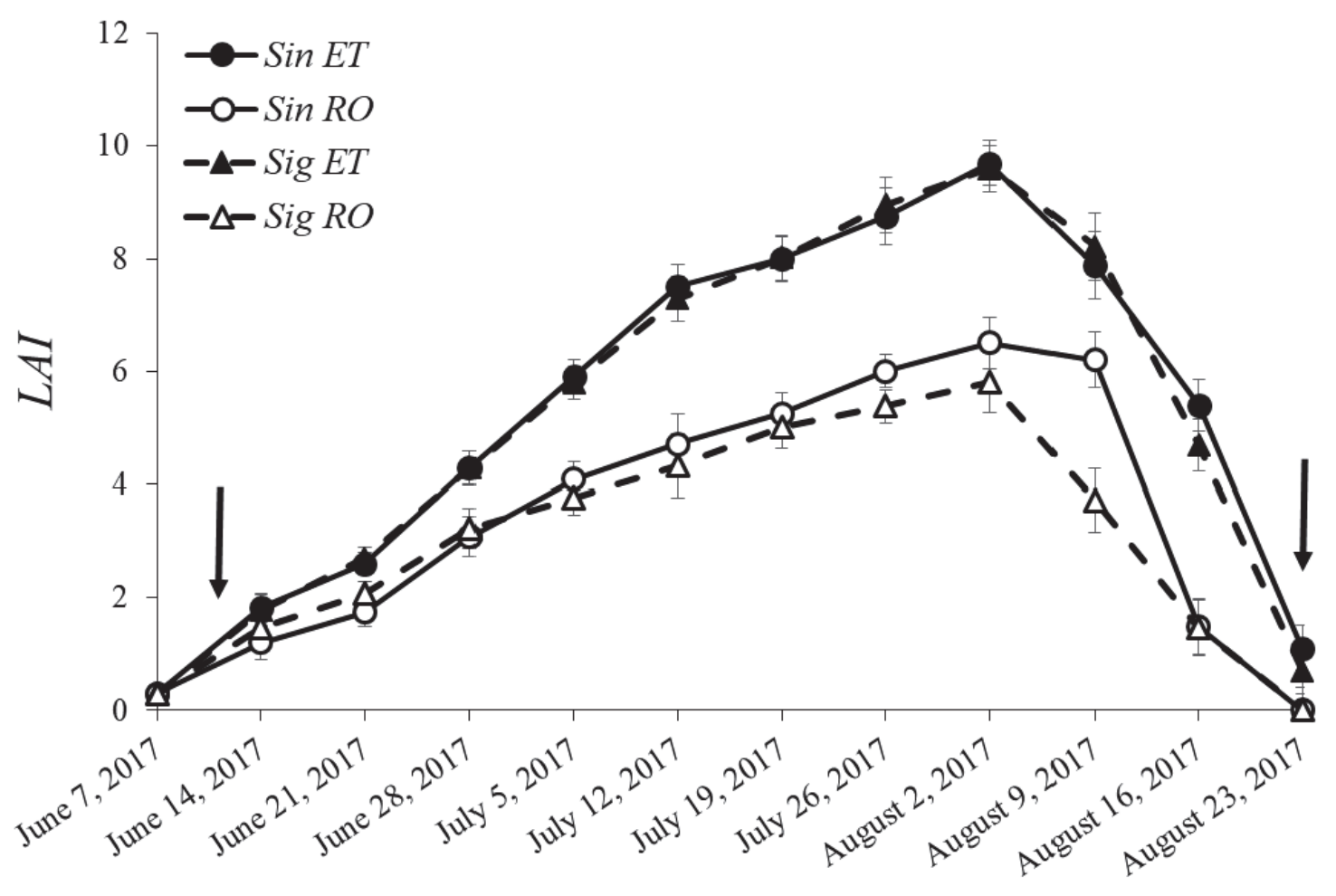

Fig. 3. Weekly variation in leaf area index (LAI) of varieties Sinara (Sin) and Sigalia (Sig) using two levels of water supply (ET: unlimited watering; $R O$ : water stressed crops) in 2017. The arrows show the beginning and end of water deprivation.

\subsection{Soybean's canopy structure}

The $L A I_{\max }$ was selected for evaluation of canopy architecture, as during this growth period (R6), the final height of crops was reached and the $L A I$ remained relatively invariable. Yang et al. (2009) concluded that $L A I_{\max }$ well reflects the impact of environmental conditions on the growth of crops. 
The average number of leaf storeys were $15.0 \pm 2.18$ and $13.5 \pm 1.75$ in $E T$ and $R O$, respectively. Due to the lower number of leaf levels, crop height in $E T$ increased with $0.13 \mathrm{~m}(p<0.001)$ comparing to the height of $R O$. Unlimited water supply stimulated the plant growth through emerging more trifoliate layers contributing to increased $L A I$.

The multiplier $x$ in Eq. (1). was determined with linear regression without intercept based on measured data of about 350 trifoliates:

$$
L=0.708 a b .
$$

Fig. 4 shows the calculated leaflet area values.

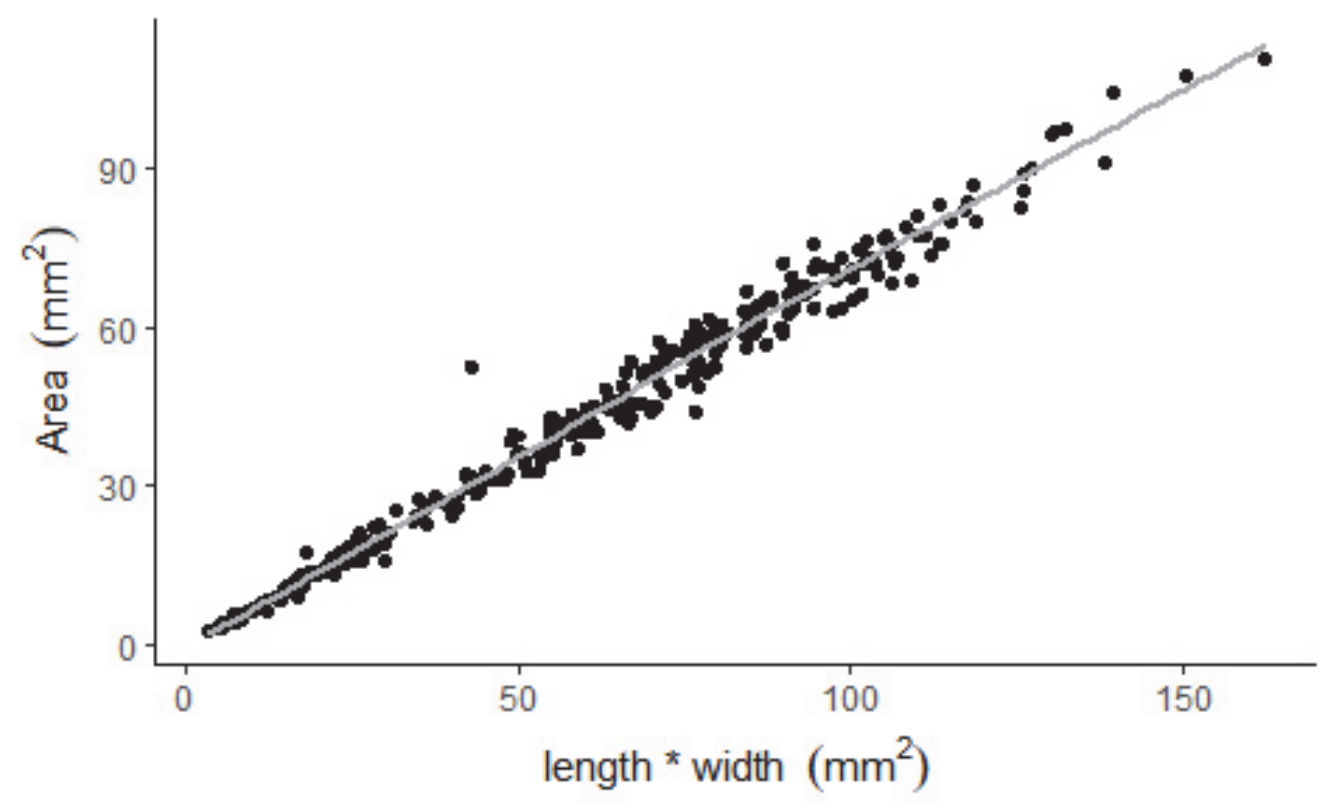

Fig. 4. Calculated leaflet area values based on Eq. (3).

The effect of the water supply was analyzed with a 3-way full factorial ANOVA. The 3-way interaction and two 2-way interactions were not significant, they were removed from the model. Finally, the main effect of the trifoliate level $\left(p=3 \cdot 10^{-10}\right)$, the water supply $(p=0.0005)$ and the water supply and variety interaction $(p=0.034)$ were found to be significant. The fact that interactions including trifoliate level were not significant shows that the effect of the water supply and the variety were much the same on each trifoliate level. To reveal the information hidden in the water supply - variety interaction, these two variables 
were combined into a single variable having four levels. The pairwise comparison was performed using the Tukey-HSD test. It pointed out that the trifoliate area was significantly lower in the case of Sig with water stress condition than in the other three groups (each $p<0.05$ ). The difference among the other three groups was not significant (Fig. 5).

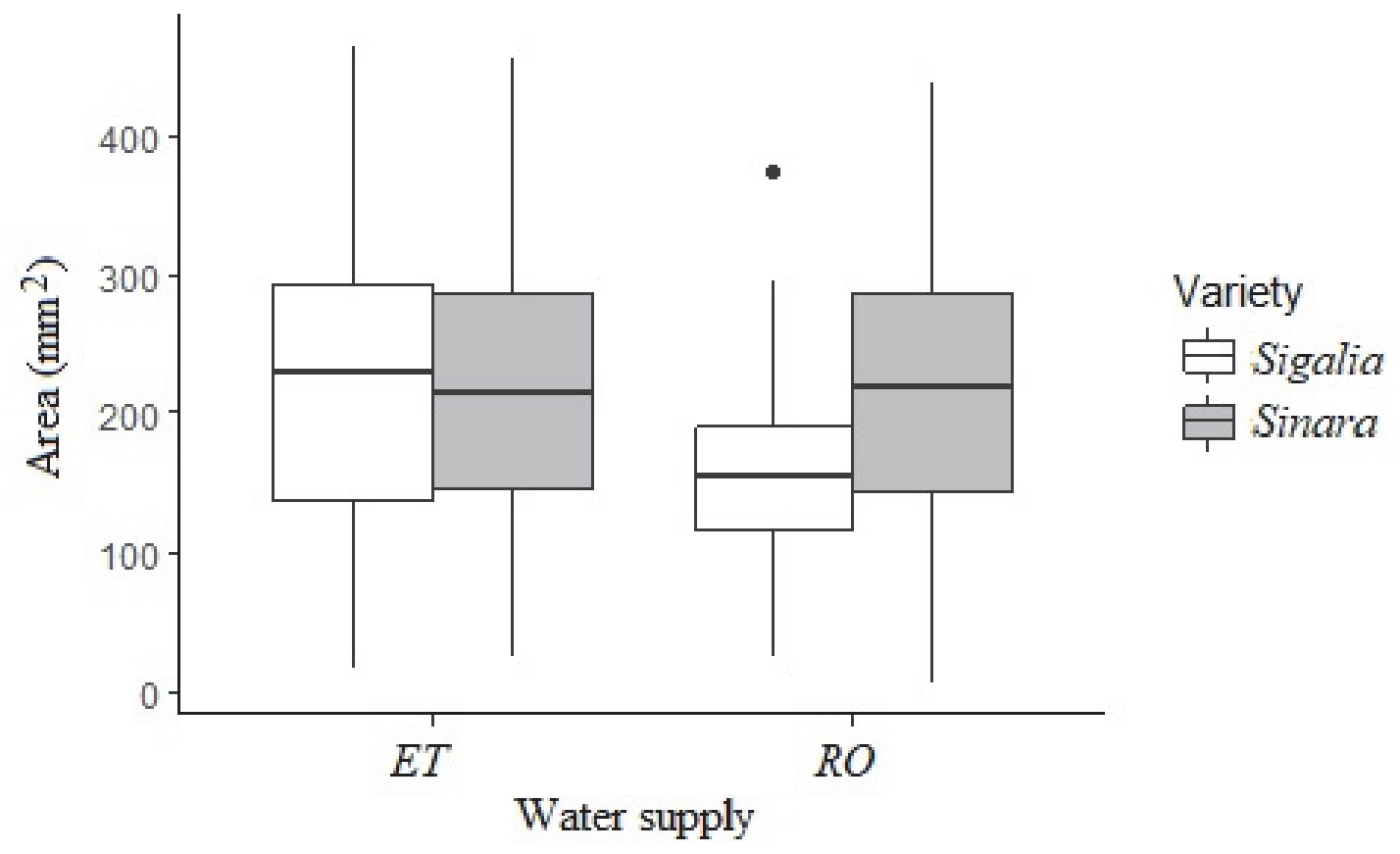

Fig. 5. Trifoliate area by water supply and variety of soybean. ET: unlimited watering, $R O$ : water stress.

Analysis was carried out on the proportion of the middle leaflet within the whole trifoliate with 3-way ANOVA model. After removing the non-significant interactions and main effects, the final model contained only the intercept. Therefore, none of the factors had significant effect on the proportion of the middle leaflet. The mean of the proportion was compared to $1 / 3$ using a onesample $t$-test. The trifoliate levels above the 13th level were excluded from the analysis due to the low sample size. The results are shown in Fig. 6. The curve is bowl-shaped, the proportion of the middle leaflet is significantly higher than $1 / 3$ on the lower four levels and from the 10th level with the exception of the 12th level. It shows that the area of the middle leaflet is approximately equal to the area of the outer ones around the center of plant height, but is greater at the bottom and the top of the plant height. 


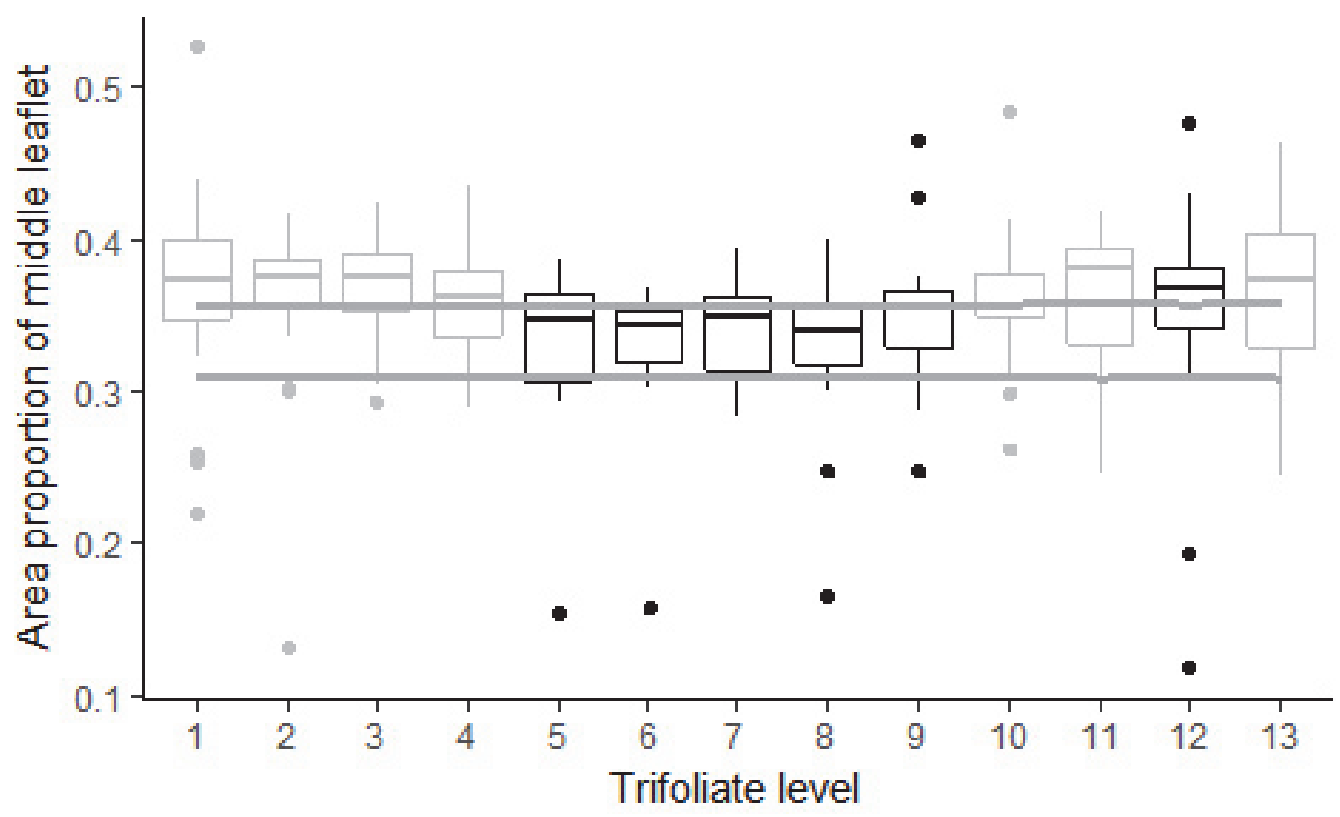

Fig. 6. Area of the middle leaflet compared to the whole area of the trifoliate. Thick grey line shows the $95 \%$ confidence interval. Boxplot is colored grey if the difference from the $1 / 3$ is significant.

\subsection{Impact of weather on the LAI}

The influence of four meteorological variables (air temperature, $T_{a}$; vapor pressure, $e_{a}$; precipitation, $P$; and wind speed, $u$ ) on the weekly mean $L A I$ of the two varieties using two levels of water supply was assessed by a correlation analysis (Table 1). Irrespective of the variety and water supply, the highest correlation coefficients $(r$ ) ranging from 0.59 (Sig RO) to 0.62 (both ET treatments) were computed between $L A I$ and $T_{a} . T_{a}$ alone explained at about 60 $62 \%$ of the variability of $L A I$. Among four studied parameters (water stress, phenology, $T_{a}$, and light use), $T_{a}$ significantly improved the vegetation production metrics, included LAI (Nguy-Robertson et al. 2015) in Nebraska, USA $\left(41.165^{\circ} \mathrm{N}\right)$. Slightly lower positive correlations of $0.46(\mathrm{Sig} R O)-0.56(\operatorname{Sin} \mathrm{RO})$ were observed between $L A I$ and $e_{a}$. Weak negative correlations $[(-0.07)-(-0.15)]$ between $L A I$ and $P$ were expected as crops were grown in evapotranspirometer under unlimited watering. Unexpectedly, negative correlation $[(-0.21)-(-0.45)]$ between $L A I$ and $u$ was found referring to the favorable effect of calm weather conditions on soybean leaf growth. The correlation between $L A I$ and $u$ was only significant in Sig $R O$, see also Table 1. The probably reason might has been that the $L A I$ values were the lowest in $\operatorname{Sig} R O$, creating the most open canopy structure mostly exposed to the influence of wind. More closed soybean stands with higher $L A I$ could hinder the impact of the wind. 
Table 1. Correlation coefficients $(r)$ for weekly measured leaf area index $(L A I)$ and weekly weather variables (weekly means of air temperature, $T_{a}$; weekly means of water vapor pressure, $e_{a}$; weekly precipitation sums, $P$; weekly mean wind speed, $u$ ) included in the study. Number of observations was 12 for each correlation.

\begin{tabular}{rllll}
\hline \hline \multicolumn{1}{c}{$\boldsymbol{L A I}$} & Sin ET & Sin RO & Sig $\boldsymbol{E T}$ & Sig $\boldsymbol{R O}$ \\
\hline \hline $\boldsymbol{T}_{\boldsymbol{a}}\left[{ }^{\circ} \mathrm{C}\right]$ & $0.62^{* *}$ & $0.61^{* *}$ & $0.62^{* *}$ & $0.59^{* *}$ \\
$\boldsymbol{e}_{\boldsymbol{a}}[\mathrm{kPa}]$ & $0.51^{* *}$ & $0.56^{* *}$ & $0.52^{* *}$ & $0.46^{* *}$ \\
$\boldsymbol{P}[\mathbf{m m}]$ & -0.15 & -0.07 & -0.14 & -0.08 \\
$\boldsymbol{u}[\mathbf{m} / \mathbf{s}]$ & -0.21 & -0.32 & -0.24 & $-0.45^{*}$ \\
\hline
\end{tabular}

* Marginally significant correlation $|r|>0.1, p<0.01$

** Marginally significant correlation $|r|>0.1, p<0.001$

All of the meteorological variables mentioned above were included in the multiple stepwise regression analysis. In this statistical analysis the variables included stepwise in the resulted equations are dimensionless. As there was hardly enough difference in $r$ between the two studied varieties $(E T: p<0.809 ; R O$ : $p<0.115$ ), their data were treated together (Table 2) when identifying regression equation. On the basis of the Akaike information criterion $(A I C)$ and the adjusted multiple correlation $\left(R^{2}\right), T_{a}$ impacted the $L A I$ the most, irrespective of water supply (in ET: $L A I=0.996 T_{a}-16.796, R^{2}=0.322, A I C=20.77$; in $R O$ : $\left.L A I=0.728 T_{a}-12.746, R^{2}=0.309, A I C=13.25\right)$. It is a favorable response as $T_{a}$ is the most easily accessible meteorological variable for all potential users including farmers. Nielsen (1990) called the attention for the importance of ambient $T_{a}$ in governing soybean's physiological processes in USDA Central Great Plains Research Statin $\left(40^{\circ} 9^{\prime} \mathrm{N}\right)$, as shown even for leaf growth in this study.

Table 2. Result of multiple stepwise regression analysis between meteorological variables and leaf area index, $L A I$ in unlimited water supply, ET and using $50 \%$ water withdrawal, $R O$. Only one meteorological variable, the air temperature $T_{a}$ remained in the regression equations. Equations included data of both varieties studied. $R$ and $A I C$ denoted coefficient of multiple correlation and Akaike Information Criterion, respectively.

\begin{tabular}{llccccc}
\hline \hline Adjusted $\boldsymbol{R}^{2}$ & $\begin{array}{c}\boldsymbol{F} \text { - } \\
\text { value }\end{array}$ & $\begin{array}{c}\text { Sig. of } \\
\boldsymbol{F}\end{array}$ & $\begin{array}{c}\text { Standard } \\
\text { Error of } \\
\text { coefficient }\end{array}$ & Regression equation & AIC \\
\hline \hline & & & & & & \\
ET & 0.322 & 6.223 & 0.032 & $\begin{array}{l}\text { Const. }=8.88 \\
T_{a}=0.399\end{array}$ & $L A I=0.996 T_{a}-16.796$ & 20.77 \\
$R O$ & 0.309 & 5.925 & 0.035 & $\begin{array}{l}\text { Const. }=6.65 \\
T_{a}=0.299\end{array}$ & $L A I=0.728 T_{a}-12.746$ & 13.25 \\
\hline
\end{tabular}




\subsection{Seed yield of the treatments}

Based on a two-way ANOVA $(F)$ test for seed yield, there were significant main effects of water supply $(F(1,16)=87.396 ; p=0.000)$ and variety $(F(1,16)=8.082 ; p=0.012)$ (The numbers in the bracket are the between-groups and the within-groups degrees of freedom separated by a comma. After the $=$ are the $F$ statistic and the significance level). The water $\mathrm{x}$ variety interaction on seed yield was not significant $(F(1,16)=1.644 ; p=0.218)$, indicating that the impact of the water supply was about the same on both varieties (Fig. 7).

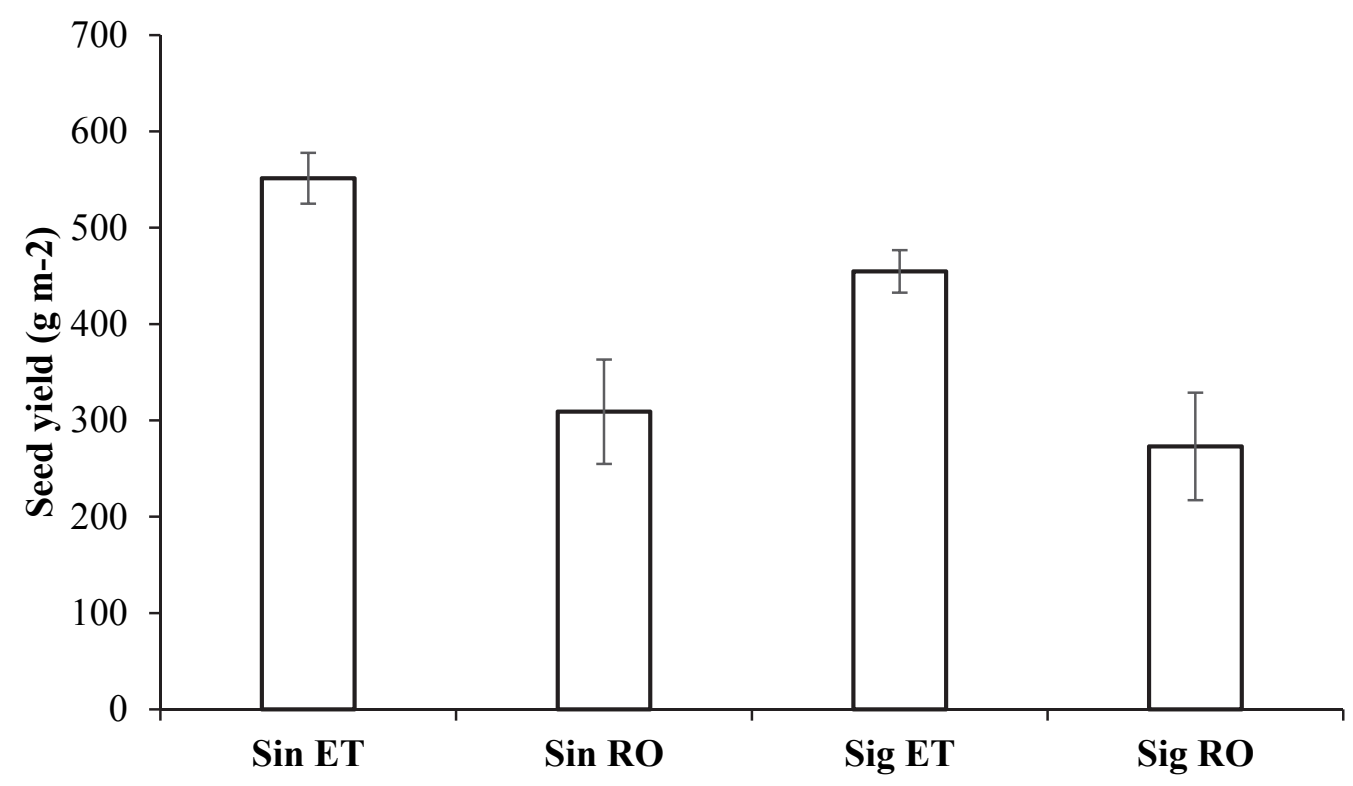

Fig. 7. Seed yield of soybean varieties Sinara (Sin) and Sigalia (Sig) in two watering levels (unlimited: $E T$; water stressed: $R O$ ).

\section{Conclusion}

Accounting different varieties and water supply levels, this study contributed to the better understanding of soybean canopy architecture. The new information - produced by the research - can widen the application related to the crop structure used in crop modeling. 
Acknowledgements: The research leading to these results has received funding from the Hungarian Government and the European Regional Development Fund of the European Union in the frames of the Széchenyi 2020 Programme, under project number GINOP-2.3.2-15-2016-00029. A special thanks to the Karintia Corporation, Hungary for their kindness supporting us by good-quality soybean seed for free.

\section{References}

Anda, A. and Soós, G., 2012: Evapotranspiration of cadmium treated maize. Növénytermelés. 61, 369-372.

Bagg, J., Banks, S., Baute, T., Bohner, H., Brown, C., Cowbrough, M., Hall, B., Hayes, A., Johnson, P., Martin, H., McDonald, I., Quesnel, G., Reid, K., Spieser, H., Stewart, G., Tenuta, A. and Verhallen, A., 2009: In (Ed.: Brown, C.), Agronomy Guide for Field Crops: Publication 811. Toronto, Ontario.

Board, J.E., Wier, A.T., and Boethel, D.J., 1997: Critical light interception during seed filling for insecticide application and optimum soybean grain yield. Agron J. 89, 369-374. https://doi.org/10.2134/agronj1997.00021962008900030001x

Bausch, W.C., 1993: Soil background effects on reflectance-based crop coefficients for corn. Remote Sens Environ. 46, 213-222. https://doi.org/10.1016/0034-4257(93)90096-G

Campos, I., Neale, C.M.U., Suyker, A.E., Arkebauer, T.J., and Gonçalves, I.Z., 2017: Reflectance-based crop coefficients REDUX: For operational evapotranspiration estimates in the age of high producing hybrid varieties. Agric. Water Manag. 187, 140-153.

Fehr, W.R. and Caviness, C.E., 1977: Stages of soybean development. Spec. Rep.80 Coop. Ext. Service. Iowa State University, Ames, Iowa.

Hsiao, T., 1990: Measurements of plant water status. In (Eds. Stewart, B.A., Nielsen, D.R.), Irrigation of Agricultural Crops. Agronomy Monogr. ASA, CSSA, SSSA, Madison, WI, 243-279.

Jonckheere, I., Fleck, S., Nackaerts, K., Muys, B., Coppin, P., Weiss, M., and Baret, F., 2004: Review of methods for in situ leaf area index determination. Part I. Theories, sensors and hemispherical photography. Agric. For. Meteor. 121, 19-35. https://doi.org/10.1016/j.agrformet.2003.08.027

Karintia, 2017: Vetőmag fajtakínálat (Seed varieties): https://karintia.hu/vetomagok/sigalia/; https://karintia.hu/vetomagok/sinara/ (in Hungarian)

Kross, A., Lapen, D.R., McNairn, H., Sunohara, M., Champagne, C., and Wilkes, G., 2015: Satellite and in situ derived corn and soybean biomass and leaf area index: Response to controlled tile drainage under varying weather conditions. Agric. Water Manag. 160, 118-131.

https://doi.org/10.1016/j.agwat.2015.06.007

Lessmann, J.M., Brix, H., Bauer, V., Clevering, O.A., and Comin, F.A., 2001: Effect of climatic gradients on the photosynthetic responses of four Phragmites australis populations. Aquatic Botany 69, 109-126. populations. Aquatic Botany 69, 109-126. https://doi.org/10.1016/S0304-3770(01)00133-4

Malone, S., Herbert, Jr. D.A., and Holshouser, D.L., 2002: Relationship between leaf area index and yield in double-crop and full-season soybean systems. J. Econ. Entom. 95, 945-951. https://doi.org/10.1093/jee/95.5.945

Motulsky, H. and Christopoulos, A., 2004: Fitting models to biological data using linear and non-linear regression. Oxford University Press, Oxford.

Montoya, F., Garcia, C., Pintos, F., and Otero, A., 2017: Effects of irrigation regime on the growth and yield of irrigated soybean in temperate humid climatic conditions. Agric. Water Manag. 193, 30-45. https://doi.org/10.1016/j.agwat.2017.08.001

Nguy-Robertson, A., Suyker, A., and Xiao, X., 2015: Modeling gross primary production of maize and soybean croplands using light quality, temperature, water stress and phenology. Agric. For. Meteor. 213, 160-172. https://doi.org/10.1016/j.agrformet.2015.04.008

Nielsen, D.C., 1990: Scheduling irrigations for soybeans with the crop water stress index (CWSI). Field Crop Res. 23, 103-116. https://doi.org/10.1016/0378-4290(90)90106-L

R Core Team, 2017. R: A language and environment for statistical computing. R Foundation for Statistical Computing, Vienna, Austria. URL: https://www.R-project.org/ 
Setiyono, T.D., Weiss, A., Specht, J.E., Cassman, K.G., and Dobermann, A., 2008: Leaf area index simulation in soybean grown under near-optimal conditions. Field Crops Res. 108, 82-92. https://doi.org/10.1016/j.fcr.2008.03.005

SPSS Statistics 17.0; IBM Corporation, New York, US.

Verrelst, J., Camps-Valls, G., Muñoz-Marí, J., Rivera, J.P., Veroustraete, F., Clevers, J.G.P.W., and Moreno, J., 2015: Optical remote sensing and the retrieval of terrestrial vegetation biogeophysical properties - A review. ISPRS J. Photogrammet. Remote Sens. 108, 273-290.

Vina, A., Gitelson, A.A., Nguy-Robertson, A.L., and Peng, Y., 2011: Comparison of different vegetation indices for the remote assessment of green leaf area index of crops. Remote Sens. Environ, 115. 3468-3478. https://doi.org/10.1016/j.rse.2011.08.010

Yang, Y., Timlin, D.J., Fleisher, D.H., Kim, S.H., Quebedeaux, B., and Reddy, V.R., 2009: Simulating leaf area of corn plants at contrasting water status. Agric For Meteor. 149, 1161-1167.

https://doi.org/10.1016/j.agrformet.2009.02.005 